\title{
Clinical Significance of INHBA Gene Expression in Patients with Gastric Cancer who Receive Curative Resection Followed by Adjuvant S-1 Chemotherapy
}

\author{
YUSUKE KATAYAMA ${ }^{1}$, TAKASHI OSHIMA ${ }^{1}$, KENTARO SAKAMAKI ${ }^{2}$, TORU AOYAMA ${ }^{1}$, \\ TSUTOMU SATO ${ }^{1}$, KATSUHIKO MASUDO ${ }^{3}$, MANABU SHIOZAWA ${ }^{4}$, \\ TAKAKI YOSHIKAWA ${ }^{4}$, YASUSHI RINO ${ }^{1}$, TOSHIO IMADA ${ }^{5}$ and MUNETAKA MASUDA ${ }^{1}$ \\ ${ }^{1}$ Department of Surgery, Yokohama City University, Yokohama, Japan; \\ Departments of ${ }^{2}$ Biostatistics and ${ }^{3}$ Breast and Thyroid Surgery, \\ Yokohama City University Medical Center, Yokohama, Japan; \\ ${ }^{4}$ Department of Gastrointestinal Surgery, Kanagawa Cancer Center, Yokohama, Japan; \\ ${ }^{5}$ Department of Surgery, Saisei-kai Yokohama-shi Nanbu Hospital, Yokohama, Japan
}

\begin{abstract}
Background: Standard treatment for stage II/III gastric cancer is curative resection followed by adjuvant chemotherapy. However, the five-year survival remains unsatisfactory. Inhibin $\beta A$ (INHBA) has been reported to be associated with cancer cell proliferation and chemoresistance. Patients and Methods: We studied the clinical significance of INHBA gene expression in 134 patients with stage II/III gastric cancer who received adjuvant chemotherapy with $S$ - 1 . INHBA expression of specimens of cancer tissue and adjacent normal mucosa was measured by quantitative real-time, reversetranscription polymerase chain reaction $(R T-P C R)$. Results: $I N H B A$ expression levels were significantly higher in cancer tissue than in adjacent normal mucosa. High INHBA expression was associated with significantly poorer 5-year survival than was low expression. On multivariate analysis, INHBA expression was an independent prognostic factor. Conclusion: INHBA gene expression in gastric cancer tissue is considered a useful independent predictor of outcomes in patients with stage II/III gastric cancer who receive adjuvant chemotherapy with $S-1$.
\end{abstract}

Gastric cancer is the third leading cause of cancer-related death in the world. In 2012, there were 723,000 deaths from

This article is freely accessible online.

Correspondence to: Takashi Oshima, MD, Ph.D., Department of Surgery, Yokohama City University, 3-9 Fukuura, Kanazawa-ku, Yokohama-shi, Kanagawa-ken 236-0004, Japan. Tel: +81 457872800, Fax: +81 457872931, e-mail: ohshimatakashi@yahoo.co.jp

Key Words: Inhibin beta A, gastric cancer, adjuvant chemotherapy. gastric cancer (1). Although good treatment outcomes are being obtained after endoscopic therapy and surgery in patients with early gastric cancer, outcomes in patients with advanced gastric cancer remain inadequate despite progress in diagnostic devices, surgical techniques and chemotherapy. Standard treatment for stage II or III gastric cancer is surgery plus fluoropyrimidine-based postoperative adjuvant chemotherapy. In Japan, the Adjuvant Chemotherapy Trial of S-1 for Gastric Cancer (ACTS-GC) obtained a 5-year survival rate of $71.7 \%$ in patients with stage II or III disease who received oral S-1 for 1 year after curative resection with D2 lymph node dissection. In the subgroups of patients with stage IIIA or stage IIIB disease, the 5-year survival rates were $67.1 \%$ and $50.2 \%$, respectively (2). These results remain unsatisfactory and hope has been placed on personalized therapy guided by biomarker analysis as a strategy that can potentially improve outcomes.

We analyzed the expression ratios of approximately 30,000 genes in gastric cancer tissue and adjacent normal gastric mucosa by DNA microarray profiling in patients with stage II or III gastric cancer who received oral S-1 for 1 year after curative resection and had early recurrence and poor treatment outcomes. When we examined overexpressed genes in gastric cancer tissue, we found that inhibin $\beta \mathrm{A}$ (INHBA) gene expression was 12.8 times higher in cancer tissue than in adjacent normal gastric mucosa, indicating overexpression of the INHBA gene in gastric cancer tissue. INHBA is a member of the transforming growth factor (TGF)- $\beta$ superfamily and recent studies have reported that the INHBA gene is overexpressed in various types of cancers, including lung (3), pancreatic (4) and colorectal cancer (5). In recent years, INHBA has been reported to have a role in cancer cell proliferation, invasion, metastasis and chemoresistance (6). 
Table I. PCR primers and conditions.

\begin{tabular}{lccc}
\hline Gene & Primer & Annealing temperature $\left({ }^{\circ} \mathrm{C}\right)$ & Product size $(\mathrm{bp})$ \\
\hline INHBA & 5'-GGTATGTGGAGATAGAGGATGAC-3' & 56.0 & 105 \\
5'-TCCTGGCTGTTCCTGACTC-3' & & 171 \\
& 5'-AGTTGCGTTACACCCTTTCTTGAC-3' & 60.0 & \\
\hline
\end{tabular}

In the present study, we examined the clinical significance of INHBA gene expression in patients with stage II or III gastric cancer who underwent curative resection followed by adjuvant chemotherapy with $\mathrm{S}-1$.

\section{Patients and Methods}

Patients and samples. We studied surgical specimens of cancer tissue and adjacent normal mucosa obtained from 134 patients with stage II or III gastric cancer who had received no preoperative therapy. The patients received curative surgery and adjuvant chemotherapy with S-1 in the Department of Surgery, Yokohama City University, Japan, and the Gastroenterological Center, Yokohama City University Medical Center and Kanagawa Cancer Center between 2002 and 2010. As a reference group, we concurrently studied INHBA status and survival in 103 patients who underwent curative resection but did not receive adjuvant S-1 chemotherapy. Informed consent was obtained from each patient, while the Ethics Committees of Yokohama City University Medical Center, Yokohama City University (approval number: 18-7A-4) and Kanagawa Cancer Center (approval number: epidemiological study-29) approved the protocol before initiation of the study. Each tissue sample was embedded in optimum cutting temperature (O.C.T.) compound (Sakura Finetechnical Co., Ltd., Tokyo, Japan) and immediately stored at $-80^{\circ} \mathrm{C}$ until use. No patient had any other malignancies. Tissue specimens were stained with hematoxylin and eosin and examined histopathologically. Sections that consisted of $>80 \%$ carcinoma cells were used to prepare total RNA.

Immunohistochemical analysis. Immunohistochemical studies of INHBA were performed on formalin-fixed, paraffin-embedded surgical specimens obtained from the patients with gastric cancer. The tissue sections were deparaffinized and soaked in $10 \mathrm{mM}$ sodium citrate buffer $(\mathrm{pH} 6.0)$ at $121^{\circ} \mathrm{C}$ for 15 minutes to retrieve cell antigens. After blocking, the sections were incubated overnight at $4{ }^{\circ} \mathrm{C}$ to allow antigen-antibody reactions to occur. Peroxidaselabeled polymer (En Vision+, rabbit; DAKO, Glostrup, Denmark) was used to detect signals of the antigen-antibody reactions. All sections were counterstained with hematoxylin. Primary polyclonal antibodies against INHBA (Atlas Antibodies, Stockholm, Sweden) were used at a dilution of 1:200.

Quantitative real-time, reverse-transcriptase polymerase chain reaction ( $R T-P C R)$. Total RNA isolated from gastric cancer tissue and adjacent normal mucosa was prepared with the use of Trizol (Gibco, Life Tech, Gaithersburg, MD, USA). Complementary DNA (cDNA) was synthesized from $0.4 \mu \mathrm{g}$ of total RNA with an iScript

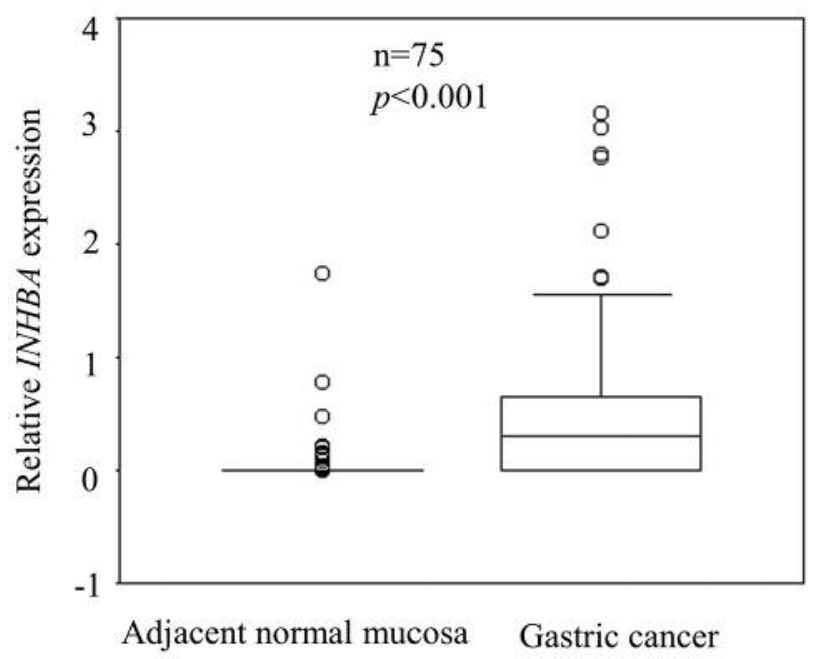

Figure 1. Comparison of inhibin $\beta A$ (INHBA) mRNA expression levels between gastric cancer tissue and adjacent normal mucosa. Box boundaries, the 25th and 75th percentiles of the observed values; capped bars, the 10th and 90th percentiles; solid line, median. p-Values were calculated by the Wilcoxon signed-rank test. Expression levels of the INHBA gene were higher in cancer than in adjacent normal mucosa $(p<0.001)$.

cDNA Synthesis Kit (Bio-Rad Laboratories, Hercules, CA, USA). After synthesis, the cDNA was diluted to $0.2 \mu \mathrm{l}$ with water and stored at $-20^{\circ} \mathrm{C}$ until use.

Quantitative real-time PCR was performed with iQ SYBR Green Supermix (Bio-Rad Laboratories). PCR reactions were carried out in a total volume of $15 \mu \mathrm{l}$, which included $0.2 \mu \mathrm{g}$ of cDNA, $0.4 \mu \mathrm{M}$ of each primer, $7.5 \mu \mathrm{l}$ of iQ SYBR Green Supermix containing dATP, dCTP, dGTP and dTTP at concentrations of $400 \mu \mathrm{M}$ each, as well as 50 units/ml of iTag DNA polymerase. The PCR consisted of 10 minutes at $95^{\circ} \mathrm{C}$, followed by 40 cycles of denaturation of the cDNA for 10 seconds at $95^{\circ} \mathrm{C}$, annealing for 10 seconds at $56^{\circ} \mathrm{C}\left(60^{\circ} \mathrm{C}\right.$ for $\beta$-actin $(A C T B)$ ) and a primer extension for $20 \mathrm{sec}$ at $72^{\circ} \mathrm{C}$, followed by $10 \mathrm{~min}$ at $72^{\circ} \mathrm{C}$. The PCR primer sequences of INHBA and $A C T B$, used as an internal control, are shown in Table I.

Statistical analysis. Gene expression levels of gastric cancer were compared with those of adjacent normal mucosa with the use of the Wilcoxon test. A univariate Cox proportional-hazards model was used to evaluate the relations of overall survival to INHBA and potential prognostic variables, including age, gender, tumor 
a

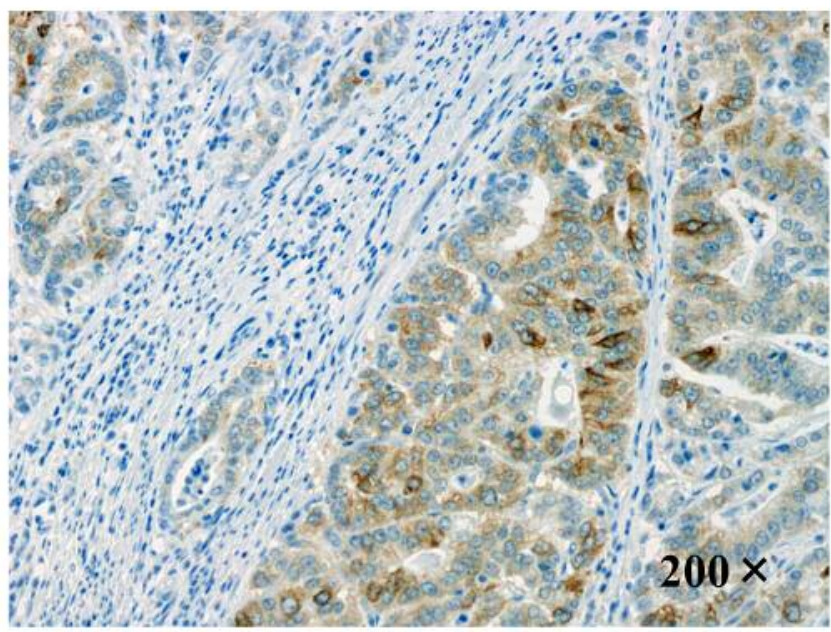

b

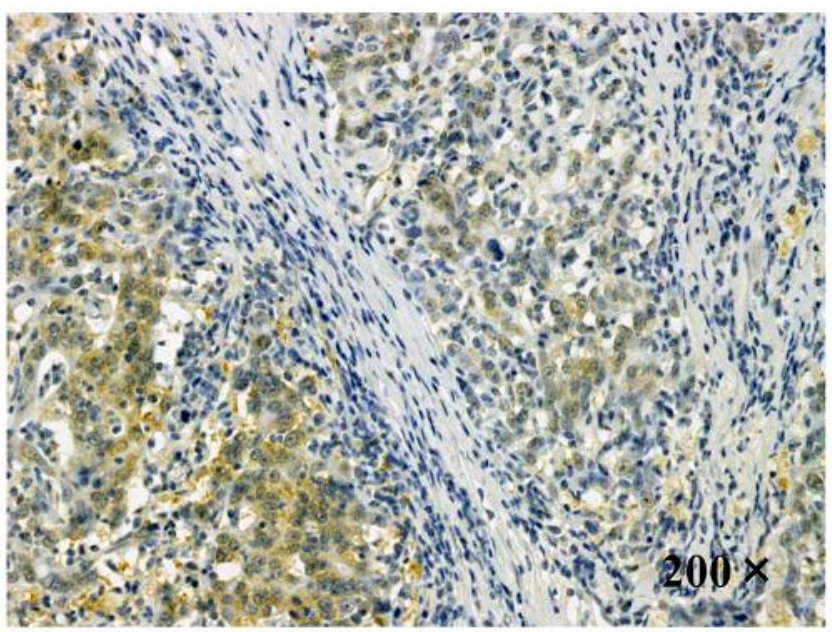

Figure 2. Immunohistochemical analysis of inhibin $\beta A$ (INHBA) expression. Expression of INHBA protein was evaluated by immunohistochemical analysis of resected specimens of gastric cancer. Positive staining for INHBA was observed in cytoplasm and was markedly more intense in human gastric cancer cells than in stromal cells, in both differentiated (a) and undifferentiated (b) types of gastric cancer.

size, histological type, depth of invasion, lymph node metastasis, lymphatic invasion, venous invasion, and tumor node metastasis (TNM) stage. Cut-off points of INHBA were evaluated in a multivariate Cox proportional-hazards model with prognostic factors that were significantly related to overall survival in the univariate analysis. "Optimal" cut-off points were selected by the minimum $p$-value method, whereas the internal validity of the cut-off points was evaluated with a two-fold cross-validation approach (7). Relations between gene expression and potential prognostic variables were evaluated using the $\chi^{2}$ test. The postoperative survival rate was analyzed by the Kaplan-Meier method and differences in survival rates were assessed with the $\log$-rank test. All $p$-values of $<0.05$ were considered to indicate statistical significance. All statistical analyses were performed using the Dr. SPSS II program, version 11.0.1J for Windows (SPSS, Inc., Chicago, IL, USA) and SAS version 9.3 (SAS Institute, Cary, NC, USA).

\section{Results}

Comparison of INHBA mRNA expression between gastric cancer tissue and adjacent normal mucosa. INHBA gene expression levels were significantly higher in cancer tissue than in adjacent normal mucosa $(p<0.001$; Figure 1).

Immunohistochemical analysis. The expression of INHBA protein was elevated on immunohistochemical analysis of resected specimens of gastric cancer. Positive staining for INHBA was observed in the cytoplasm of gastric cancer cells and not found in stromal cells in either differentiated or undifferentiated types of gastric cancer (Figure 2).
Univariate and multivariate analyses of the relations of clinicopathological features and INHBA gene expression levels to outcomes. TNM stage was related to overall survival in univariate analysis. When 0.751 was used as the cut-off point for INHBA gene expression levels, the $p$-value was smallest in a multivariate Cox proportional-hazards model, including TNM stage. A two-fold cross-validation approach showed that categorized INHBA gene expression $(p<0.001)$ and TNM stage $(p=0.026)$ were significantly related to overall survival (Table II).

Relations of INHBA gene expression levels to clinicopathological features. Study samples were divided into two groups (low-expression group, $n=97$; highexpression group, $\mathrm{n}=37$ ) according to the expression level of INHBA mRNA (cut-off point=0.751). Relations between $I N H B A$ gene expression and clinicopathological features were then examined. INHBA gene expression levels were not related to any clinicopathological feature (Table III).

Survival curves according to INHBA mRNA expression levels. In stage II disease, the 5-year overall survival rate was poorer in patients with high INHBA expression than in those with low INHBA expression (log-rank $p$-value $=0.08$; Figure $3 a)$. In stage III disease, the 5-year overall survival rate was poorer in patients with high INHBA expression than in those with low INHBA expression (log-rank $p<0.001$; Figure $3 b$ ). In the study group as a whole, the 5-year overall survival was poorer in patients with high INHBA expression than in 
in vivo $31: 565-571(2017)$

Table II. Univariate and multivariate analysis of clinicopathological features for overall survival.

\begin{tabular}{|c|c|c|c|c|c|c|c|}
\hline \multirow[b]{2}{*}{ Variable/category } & \multirow[b]{2}{*}{$\mathrm{n}$} & \multicolumn{3}{|c|}{ Univariate } & \multicolumn{3}{|c|}{ Multivariate } \\
\hline & & Hazard ratio & $95 \% \mathrm{CI}$ & $p$-Value & Hazard ratio & $95 \% \mathrm{CI}$ & $p$-Value \\
\hline Age (years) & & & & 0.25 & & & \\
\hline$<65$ & 56 & 1 & & & & & \\
\hline$>65$ & 78 & 0.673 & $0.343-1.321$ & & & & \\
\hline Gender & & & & 0.255 & & & \\
\hline Female & 42 & 1 & & & & & \\
\hline Male & 92 & 1.585 & $0.717-3.502$ & & & & \\
\hline Histological type & & & & 0.812 & & & \\
\hline Differentiated & 53 & 1 & & & & & \\
\hline Undifferentiated & 81 & 0.92 & $0.465-1.823$ & & & & \\
\hline Tumor size $(\mathrm{cm})$ & & & & 0.813 & & & \\
\hline$<6$ & 60 & 1 & & & & & \\
\hline$>6$ & 74 & 1.085 & $0.551-2.137$ & & & & \\
\hline Serosal invasion & & & & 0.365 & & & \\
\hline Absent & 53 & 1 & & & & & \\
\hline Present & 81 & 1.395 & $0.679-2.864$ & & & & \\
\hline Lymph node metastasis & & & & 0.102 & & & \\
\hline Absent & 16 & 1 & & & & & \\
\hline Present & 118 & 5.268 & $0.720-38.538$ & & & & \\
\hline TNM stage & & & & 0.033 & & & 0.026 \\
\hline Stage II & 40 & 1 & & & 1 & & \\
\hline Stage III & 94 & 2.808 & $1.086-7.259$ & & 2.941 & $1.135-7.621$ & \\
\hline Lymphatic invasion & & & & 0.537 & & & \\
\hline Absent & 30 & 1 & & & & & \\
\hline Present & 104 & 1.32 & $0.546-3.192$ & & & & \\
\hline Venous invasion & & & & 0.232 & & & \\
\hline Absent & 33 & 1 & & & & & \\
\hline Present & 101 & 1.712 & $0.709-4.136$ & & & & \\
\hline \multirow[t]{3}{*}{ INHBA (Continuous) } & & & & 0.06 & & & \\
\hline & & 1 & & & & & \\
\hline & & 1.173 & $0.709-4.136$ & & & & \\
\hline INHBA (Binary) & & & & $<0.001$ & & & $<0.001$ \\
\hline Low & 97 & 1 & & & 1 & & \\
\hline High & 37 & 3.926 & $1.981-7.778$ & & 4.052 & $2.037-8.062$ & \\
\hline
\end{tabular}

CI, Confidence interval; TNM, tumor node metastasis.

those with low INHBA expression (log-rank $p<0.001$; Figure $3 c)$. Figure 4 shows the survival curves for the reference group of patients with stage II or III gastric cancer who underwent curative resection but did not receive adjuvant chemotherapy with S-1. There was no difference in survival between the patients with high INHBA expression and those with low expression $(p=0.753)$.

\section{Discussion}

In the present study, we measured INHBA gene expression in cancer tissue and adjacent normal mucosa in patients with stage II or III gastric cancer who received curative resection followed by adjuvant chemotherapy with S-1 and examined the relationships of relative INHBA gene expression levels to clinicopathological factors and treatment outcomes.
First, we compared INHBA mRNA expression levels between cancer tissue and adjacent normal mucosa in patients with stage II or III gastric cancer. Ye et al. reported that INHBA expression is significantly up-regulated in oral squamous cell carcinoma of the tongue compared to expression levels in normal tissues (8). Wildi et al. found that activin A, a homodimer of INHBA, is overexpressed in human colorectal tumors as compared with normal tissues, especially in stage IV disease (9). Our results showed that INHBA gene expression was significantly higher in cancer tissue than in adjacent normal gastric mucosa, consistent with the findings of these previous studies.

Next, we examined the relation between INHBA mRNA expression levels and clinicopathological factors. Lee et al. found that increased INHBA expression is significantly associated with pathological $\mathrm{T}$ status and lymph node 
Table III. Relation between INHBA gene expression and clinicopathological features.

\begin{tabular}{|c|c|c|c|}
\hline \multirow[b]{2}{*}{ Variable/category } & \multicolumn{2}{|c|}{$I N H B A$ mRNA expression } & \multirow[t]{2}{*}{$p$-Value } \\
\hline & High $(n=37)$ & Low $(n=97)$ & \\
\hline Age (years) & & & 0.334 \\
\hline$<65$ & 18 & 38 & \\
\hline$\geq 65$ & 19 & 59 & \\
\hline Gender & & & 0.306 \\
\hline Female & 9 & 33 & \\
\hline Male & 28 & 64 & \\
\hline Histological type & & & 0.846 \\
\hline Differentiated & 14 & 39 & \\
\hline Undifferentiated & 23 & 58 & \\
\hline Tumor size $(\mathrm{cm})$ & & & 0.848 \\
\hline$<6$ & 16 & 44 & \\
\hline$\geq 6$ & 21 & 53 & \\
\hline Serosal invasion & & & 0.846 \\
\hline Absent & 14 & 39 & \\
\hline Present & 23 & 58 & \\
\hline Lymph node metastasis & & & 1 \\
\hline Absent & 4 & 12 & \\
\hline Present & 33 & 85 & \\
\hline Lymphatic invasion & & & 0.647 \\
\hline Absent & 7 & 23 & \\
\hline Present & 30 & 74 & \\
\hline Venous invasion & & & 0.662 \\
\hline Absent & 8 & 25 & \\
\hline Present & 29 & 72 & \\
\hline TNM stage & & & 0.833 \\
\hline Stage II & 10 & 30 & \\
\hline Stage III & 27 & 67 & \\
\hline
\end{tabular}

TNM, Tumor node metastasis.

metastasis in urothelial carcinoma (10). Chang et al. showed that overexpression of immunohistochemically-detected activin A, a homodimer of INHBA, correlates with lymph node metastasis, histological differentiation and perineural invasion in oral squamous cell carcinoma (11). In our study, $I N H B A$ gene expression levels did not correlate with any clinicopathological factor.

Finally, we examined the relation between INHBA mRNA expression levels and outcomes in patients who underwent curative resection of stage II or III gastric cancer, followed by adjuvant chemotherapy with S-1. Wang et al. found that patients with higher INHBA expression levels have shorter disease-free survival and overall survival in gastric cancer (12). Lee et al. reported that high expression of INHBA correlates with poorer disease-specific survival and metastasis-free survival in urothelial carcinoma (10). In our study, high INHBA mRNA expression was associated with significantly poorer treatment outcomes than was low expression in patients with stage II or III gastric cancer who received curative resection followed by adjuvant chemotherapy with S-1. In addition, multivariate analysis using a Cox proportional-hazards model showed that high $I N H B A$ mRNA expression was an independent prognostic factor for poor outcomes. On the other hand, in patients who did not receive adjuvant therapy with $\mathrm{S}-1$, the survival rate did not differ significantly between patients with high $I N H B A$ mRNA expression and those with low expression. These findings suggest that high INHBA mRNA expression in gastric cancer tissue might indicate a high risk in patients with stage II or III gastric cancer who receive curative resection followed by adjuvant chemotherapy with S-1. Such patients are likely to require closer follow-up and combination of S-1 with other anticancer agents, although further studies are needed for confirmation.

The mechanism by which INHBA gene expression influences outcomes in gastric cancer remains to be fully investigated. In esophageal cancer, $\mathrm{N}$-cadherin induced by activin A, a homodimer of INHBA, has been reported to promote cancer cell proliferation and infiltration (13). Activin A promotes metalloproteinase-7 (MMP-7) activation (14) and facilitates cancer cell infiltration and lymphovascular invasion in gastric cancer, which may influence outcomes (15). INHBA, a member of the TGF- $\beta$ superfamily, is intimately involved in epithelial-mesenchymal transition (EMT), similar to other members of the TGF- $\beta$ superfamily. INHBA gene expression has, thus, been reported to participate in cancer invasion and metastasis $(16,17)$. As for the relation to $S-1$, activin A was reported to induce EMT in cancer (18); EMT in cancer is thought to have a role in resistance to 5fluorouracil. Arumugam et al. reported that pancreatic cancer cell lines that were resistant to 5-fluorouracil and other anticancer agents showed EMT gene expression patterns (19). Terashima et al. showed that breast cancer cell lines in which EMT was induced by TGF- $\beta$ had decreased sensitivity to 5fluorouracil (20). As for the underlying mechanism, Zhang et al. reported that cancer may induce expression of Snail, a transcription factor that has a fundamental role in EMT, enhance DNA repair of tumor cells and increase resistance to apoptosis, resulting in resistance to anticancer agents, such as 5-fluorouracil (21). High INHBA gene expression may, thus, be a poor prognostic factor in patients who receive postoperative adjuvant chemotherapy with S- 1 . However, further studies are needed to verify this hypothesis.

In conclusion, INHBA gene expression was significantly higher in cancer tissue than in normal tissue. INHBA gene overexpression was an independent predictor of poor outcomes after adjuvant therapy with S-1 in patients with stage II or III gastric cancer. Our results suggest that INHBA mRNA expression in gastric cancer tissue might be a useful prognostic biomarker in patients with stage II or III gastric cancer who receive adjuvant chemotherapy with S-1 after curative resection. 


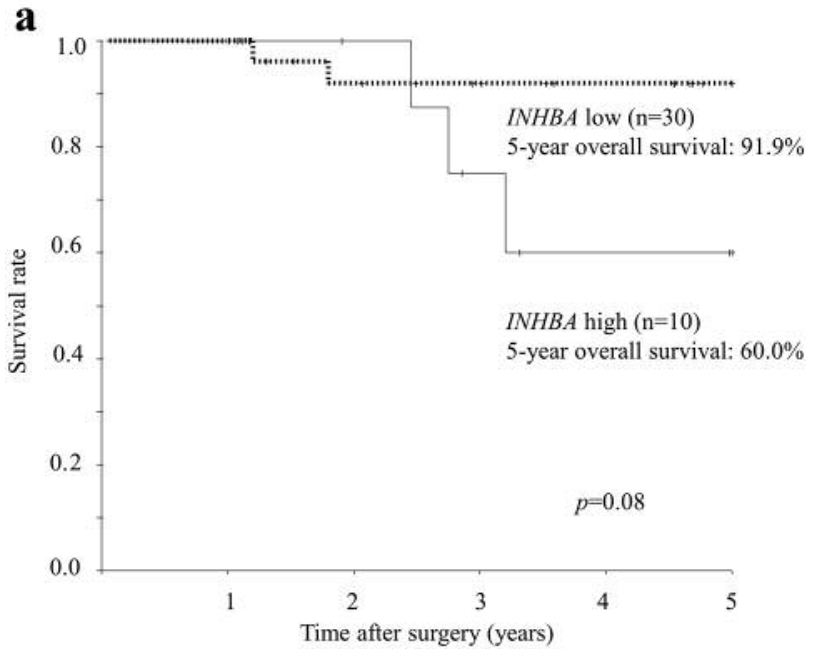

b

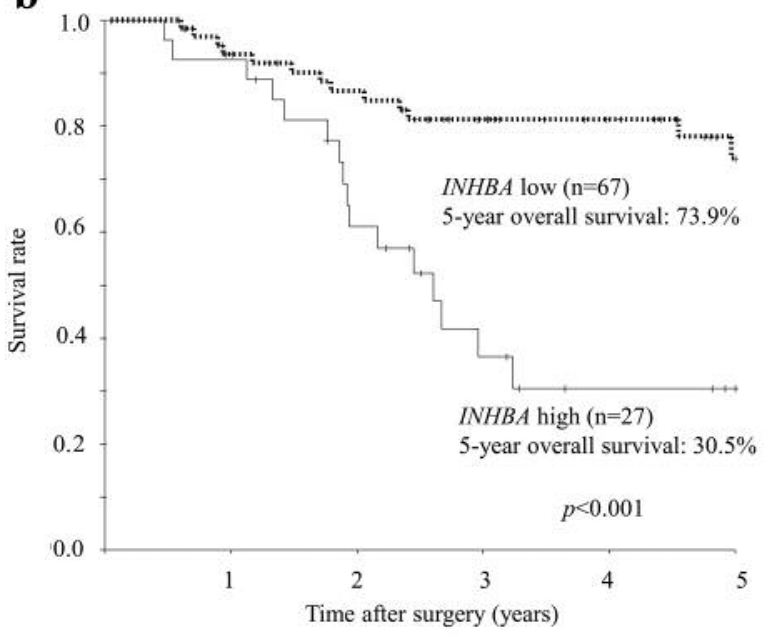

\section{Acknowledgements}

The Authors thank Kazue Yoshihara for her technical support.

\section{References}

1 Ferlay J, Soerjomataram I, Dikshit R, Eser S, Mathers C, Rebelo M, Parkin DM, Forman D and Bray F: Cancer incidence and mortality worldwide: Sources, methods and major patterns in GLOBOCAN 2012. Int J Cancer 136: E359-E386, 2015.

2 Sasako M, Sakuramoto S, Katai H, Kinoshita T, Furukawa H, Yamaguchi T, Nashimoto A, Fujii M, Nakajima T and Ohashi Y: Five-year outcomes of a randomized phase III trial comparing adjuvant chemotherapy with $\mathrm{S}-1$ versus surgery alone in stage II or III gastric cancer. J Clin Oncol 29: 4387-4393, 2011.

3 Seder CW, Hartojo W, Lin L, Silvers AL, Wang Z, Thomas DG, Giordano TJ, Chen G, Chang AC, Orringer MB and Beer DG: Upregulated INHBA expression may promote cell proliferation and is associated with poor survival in lung adenocarcinoma. Neoplasia (New York, NY) 11: 388-396, 2009.

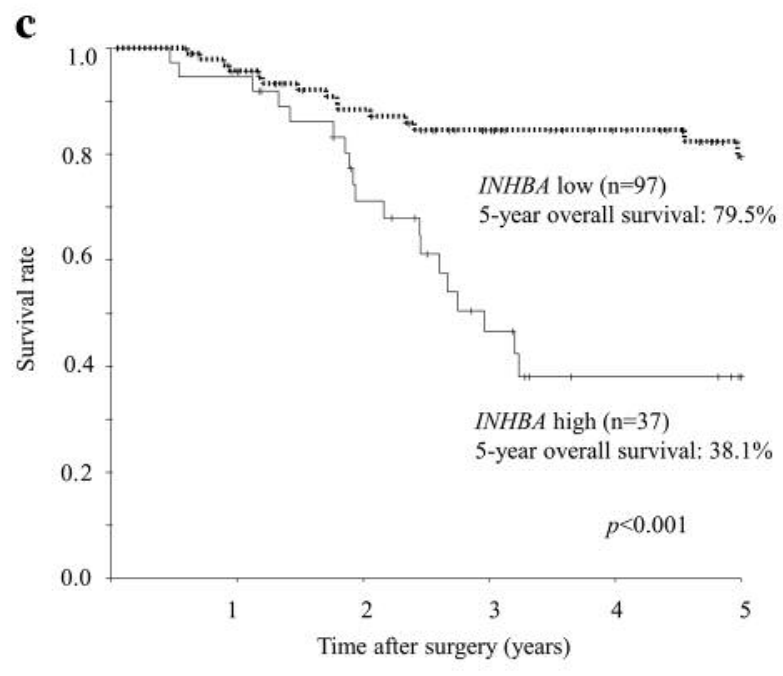

Figure 3. Relation between inhibin $\beta A$ (INHBA) mRNA expression and postoperative survival. a: In stage II disease, the 5-year overall survival rate was poorer in patients with high INHBA expression (60.0\%) than in those with low INHBA expression (91.9\%; $p=0.08)$. All p-values were calculated by the log-rank test. b: In stage III disease, the 5-year overall survival rate was significantly poorer in patients with high INHBA expression $(30.5 \%)$ than in those with low INHBA expression (73.9\%; $p<0.001)$. All p-values were calculated by the log-rank test. $c$ : In the study group as a whole, the 5-year overall survival rate was significantly poorer in patients with high INHBA expression (38.1\%) than in those with low INHBA expression $(79.5 \%$; $p<0.001)$. All $p$ values were calculated by the log-rank test.

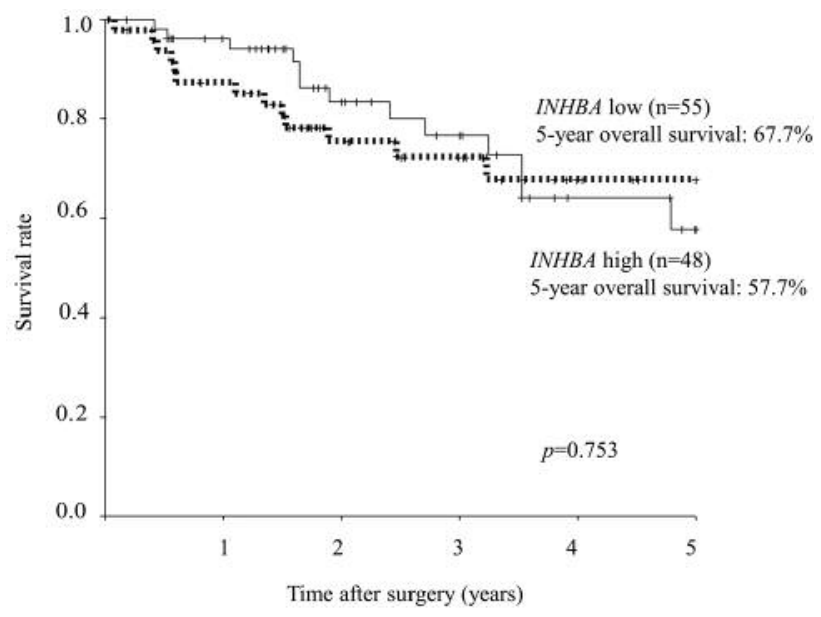

Figure 4. Comparison of survival between negative and positive expression of the inhibin $\beta A$ (INHBA) gene in stage II or III gastric cancer without $S$-1 adjuvant chemotherapy. There was no difference in the 5-year overall survival rate between the patients with high INHBA expression and those with low expression $(p=0.753)$. All $p$-values were calculated by the log-rank test. 
4 Kleeff J, Ishiwata T, Friess H, Buchler MW and Korc M: Concomitant over-expression of activin/inhibin beta subunits and their receptors in human pancreatic cancer. Int J Cancer 77: 860868, 1998.

5 Okano M, Yamamoto H, Ohkuma H, Kano Y, Kim H, Nishikawa S, Konno M, Kawamoto K, Haraguchi N, Takemasa I, Mizushima T, Ikeda M, Yokobori T, Mimori K, Sekimoto M, Doki Y, Mori M and Ishii H: Significance of INHBA expression in human colorectal cancer. Oncol Rep 30: 2903-2908, 2013.

6 Yoshinaga K, Yamashita K, Mimori K, Tanaka F, Inoue H and Mori M: Activin a causes cancer cell aggressiveness in esophageal squamous cell carcinoma cells. Ann Surg Oncol 15: 96-103, 2008.

7 Mazumdar M, Smith A and Bacik J: Methods for categorizing a prognostic variable in a multivariable setting. Stat Med 22: 559571, 2003

8 Ye H, Yu T, Temam S, Ziober BL, Wang J, Schwartz JL, Mao L, Wong DT and Zhou X: Transcriptomic dissection of tongue squamous cell carcinoma. BMC Genomics 9: 69, 2008.

9 Wildi S, Kleeff J, Maruyama H, Maurer CA, Buchler MW and Korc M: Overexpression of activin A in stage IV colorectal cancer. Gut 49: 409-417, 2001.

10 Lee HY, Li CC, Huang CN, Li WM, Yeh HC, Ke HL, Yang KF, Liang PI, Li CF and Wu WJ: INHBA overexpression indicates poor prognosis in urothelial carcinoma of urinary bladder and upper tract. J Surg Oncol 111: 414-422, 2015.

11 Chang KP, Kao HK, Liang Y, Cheng MH, Chang YL, Liu SC, Lin YC, Ko TY, Lee YS, Tsai CL, Wang TH, Hao SP and Tsai $\mathrm{CN}$ : Overexpression of activin $\mathrm{A}$ in oral squamous cell carcinoma: Association with poor prognosis and tumor progression. Ann Surg Oncol 17: 1945-1956, 2010.

12 Wang Q, Wen YG, Li DP, Xia J, Zhou CZ, Yan DW, Tang HM and Peng ZH: Upregulated INHBA expression is associated with poor survival in gastric cancer. Med Oncol 29: 77-83, 2012.

13 Yoshinaga $\mathrm{K}$, Inoue $\mathrm{H}$, Utsunomiya $\mathrm{T}$, Sonoda $\mathrm{H}$, Masuda $\mathrm{T}$, Mimori K, Tanaka $\mathrm{Y}$ and Mori M: N-cadherin is regulated by activin $\mathrm{A}$ and associated with tumor aggressiveness in esophageal carcinoma. Clin Cancer Res 10: 5702-5707, 2004.
14 Yoshinaga K, Mimori K, Inoue H, Kamohara Y, Yamashita K, Tanaka F and Mori M: Activin A enhances MMP-7 activity via the transcription factor AP-1 in an esophageal squamous cell carcinoma cell line. Int J Oncol 33: 453-459, 2008.

15 Honda M, Mori M, Ueo H, Sugimachi K and Akiyoshi T: Matrix metalloproteinase-7 expression in gastric carcinoma. Gut 39: 444-448, 1996.

16 Massague J: TGFbeta in cancer. Cell 134: 215-230, 2008.

17 Wamsley JJ, Kumar M, Allison DF, Clift SH, Holzknecht CM, Szymura SJ, Hoang SA, Xu X, Moskaluk CA, Jones DR, Bekiranov $\mathrm{S}$ and Mayo MW: Activin upregulation by NFkappaB is required to maintain mesenchymal features of cancer stem-like cells in non-small cell lung cancer. Cancer Res 75: 426-435, 2015

18 Bauer J, Ozden O, Akagi N, Carroll T, Principe DR, Staudacher JJ, Spehlmann ME, Eckmann L, Grippo PJ and Jung B: Activin and TGFbeta use diverging mitogenic signaling in advanced colon cancer. Mol Cancer 14: 182, 2015.

19 Arumugam T, Ramachandran V, Fournier KF, Wang H, Marquis L, Abbruzzese JL, Gallick GE, Logsdon CD, McConkey DJ and Choi W: Epithelial to mesenchymal transition contributes to drug resistance in pancreatic cancer. Cancer Res 69: 5820-5828, 2009.

20 Terashima M, Sakai K, Togashi Y, Hayashi H, De Velasco MA, Tsurutani $\mathrm{J}$ and Nishio K: Synergistic antitumor effects of S-1 with eribulin in vitro and in vivo for triple-negative breast cancer cell lines. SpringerPlus 3: 417, 2014.

21 Zhang W, Feng M, Zheng G, Chen Y, Wang X, Pen B, Yin J, Yu $\mathrm{Y}$ and $\mathrm{He} \mathrm{Z}$ : Chemoresistance to 5-fluorouracil induces epithelial-mesenchymal transition via up-regulation of Snail in MCF7 human breast cancer cells. Biochem Biophys Res Commun 417: 679-685, 2012.

Received April 1, 2017

Revised May 14, 2017

Accepted May 15, 2017 